\title{
CONTRACT SPECIFICITY AND ITS PERFORMANCE IMPLICATIONS
}

\author{
Erik A. Mooi \\ Assistant Professor of Marketing \\ $V U$ University Amsterdam \\ and \\ Mrinal Ghosh \\ W. "H" and Callie Clark Associate Professor of Marketing \\ University of Arizona
}

Acknowledgements: The authors thank the Steinmetz Archive and the department of sociology, Utrecht University for making the data available. In addition, we would like to thank the seminar participants from the Marketing Science Conference, Warwick Business School, Eindhoven University, Tilburg University, Imperial College, London, and of the Eller College of Management at the University of Arizona, for their valuable suggestions.

Please address all correspondence to:

Professor Mrinal Ghosh

Department of Marketing

Eller College of Management

University of Arizona

1130 E Helen Street,

Tucson, AZ 85721

Ph.: 5206267353

Email:mghosh@email.arizona.edu 


\title{
CONTRACT SPECIFICITY AND ITS PERFORMANCE IMPLICATIONS
}

\begin{abstract}
Governance theories like Transaction Cost Economics argue that systematic deviations from an attribute-governance alignment should influence performance. This paper investigates the performance implications of contract specificity for the procurement of Information Technology (IT) products. We argue that parties choose a level of contract specificity that economizes on both the ex ante contracting costs and the ex post transaction costs and that deviations between the observed and expected levels of contract specificity are an important determinant of these transaction costs. We test the hypotheses using a comprehensive archival dataset of IT transactions and employ a two-step estimation procedure. First, we estimate the "expected" level of contract specificity that account for key transactional attributes. We then study the consequences of deviating from this expected level of contractual specificity. We find that "unexpected" specificity in contracts reduces ex post transaction problems but increases ex ante contracting costs. The results provide the first explicit demonstration of the trade-off between upfront contracting costs and ex post transaction problems and suggest that parties have to economize jointly on these costs while choosing the governance form. Implications for research and practice are drawn.
\end{abstract}

Keywords: Business-to-business marketing, Contracts, Relationship marketing, Transaction Cost Economics 


\section{INTRODUCTION}

Governance theories like transaction cost economics (TCE) have been primarily used to shed light on the design of buyer-seller relationships in a wide variety of business-to-business settings with the core organizing principle being that costly governance structures are consciously engineered to account for transactional hazards (Williamson 1985). Increasingly, researchers have focused on investigating the links between such governance arrangements and performance. For instance, studies show that relational norms and processes improve relational performance (Lusch and Brown 1996; Zaheer, McEvily, and Perrone 1998) and lower customer firm costs (Cannon and Homburg 2001) and that detailed contracts reduce opportunism but only in conjunction with close partner selection and network embeddedness (Wuyts and Geyskens 2005). Houston and Johnson (2000), in contrast, argue and find that there should be no difference in performance between joint ventures and contracts. Despite these advances, two key gaps remain in our understanding on these governance-performance effects.

First, a key implication of TCE's normative rule is that if governance structures are chosen to account for hazards posed by transactional attributes, deviating from the proper attribute-governance alignment should adversely influence performance. Direct evidence of the costs of misaligned governance is a crucial test of the logic underlying TCE (Anderson 1988) because lack of such evidence provokes the question: Does governance matter? Substantively, understanding the costs of misaligned governance is critical to managerial practice because designing appropriate governance structures requires costly managerial effort and valuable organizational resources. There is however, scant though growing, empirical evidence on the costs of misaligned governance (exceptions include Anderson 1988; Berkowitz, Jap, and Nickerson 2006; Ghosh and John 2009).

Second, and relatedly, constructing governance mechanisms is itself a costly enterprise; hence, their value in curbing hazards should be balanced with their upfront set-up and design costs. Extant research, however, provides no insights on these counter-balancing aspects and its implications for governance design. Understanding this inter-play between multiple dimensions of cost (e.g., between 
ex ante design and ex post hazard costs) is of substantive importance because if ex ante design costs inhibit parties from choosing governance forms that reduce the costs of ex post hazards, managers need to be cognizant of these trade-offs while they strategically design governance ties.

We address these two key questions in this paper. Specifically, our goal is to investigate (a) whether systematic departure from the theoretically predicted level of governance influences ex ante and ex post costs and (b) whether the impact of this deviation suggests a trade-off between ex ante contracting costs and ex post hazards. To test these objectives, we use a two-step approach in the context of procurement contracts between buying firms and vendors of information technology (IT) products/services. To set-up our key hypotheses, we first use TCE to argue that lock-in, transaction complexity, and measurement ambiguity concerns determine the level of specificity, or detail, in these IT contracts. This provides us the expected (or predicted) level of contract specificity that accounts for these transactional hazards. We then construct the deviation between the observed ${ }^{1}$ and the predicted contract specificity and test the impact of this deviation on two distinct but counter-balancing dimensions of performance, viz. ex ante contracting costs and ex post transaction costs. The joint analysis of these two types of costs represents the core trade-off far-sighted managers have to make; i.e. construct contracts that are not too costly to design, yet are specific enough to reduce ex post hazards.

The analysis on a comprehensive archival dataset of procurement contracts between Dutch buying firms and their IT vendors provides strong support to our thesis. Contract specificity increases with buyer lock-in and transaction complexity but decreases with ambiguity in measuring the quality of the product. After accounting for this endogeneity, we find that deviations from the expected level of specificity have a contrasting pattern of impact on costs. Specifically, contracts that are more (less) specific than expected lower (raise) ex post transaction costs but raise (lower) ex ante contracting costs. We obtain these results even after using a stronger test that controls for heterogeneous firmspecific effects. In essence, we find that attempts to lower ex post costs, by designing contracts that 
are more detailed than expected, increase ex ante contracting costs and vice versa, suggesting that parties that seek to over-coordinate (i.e. make contracts more specific than necessary) or undercoordinate (i.e. make contracts less specific than necessary) need to balance the ex ante with ex post costs vis-à-vis their theory predicted levels. To the best of our knowledge, this is the first study to jointly investigate and demonstrate this important trade-off between ex ante contracting costs and ex post transaction costs and its joint implications on contract design.

\section{CONCEPTUAL FRAMEWORK AND HYPOTHESES}

\section{The Role of Contracts}

Exchange is central to marketing and a contract is an agreement between parties involved in the exchange of a product or service. Contracts can be explicit, legal agreements or implicit, normative agreements (Macneil 1980); regardless, their central purpose is to define the subject matter of the exchange in sufficient detail to create a shared set of rules, procedures, responsibilities, and expectations (Gilson 1984; Lusch and Brown 1996). The creation of these shared expectations, or "meeting of the minds", is of value in both simple and complex transactions. For instance, in simple exchanges a contract might specify the product, its price, and its delivery schedule. In contrast, in volatile environments where delineating future conditions, time horizons, and potential contingent responses is a formidable task, a contract not only creates a common language that conveys information (e.g., price, technical specifications, warranties, etc.) but also identifies mutually agreeable set of rights, duties, and responsibilities and how parties will interact and deal with each other (Hill and King 2004). The creation of this common language and homogeneous expectations, through both legal (i.e. explicit) and extra-legal (i.e. normative or social) terms, helps curb wasteful renegotiation and other strategic behavior. As such, contracts become mechanisms that create value by reducing the risk and uncertainty in exchange relationships (Lusch and Brown 1996).

\section{A Schema of Contract Specificity}

In technology markets where technical change is rapid and products/services are tailored to customer 
needs, these contracts often go beyond a boilerplate "bill of sale" and are specifically constructed to reflect exchange characteristics. These "customized" contracts may detail, for instance, the level of coordination, potential adjustments, and implementation activities that need be undertaken. Our focus is on the presentiation (Macneil 1980) or the extent to which these formal contract terms vary in their level of specificity or explicitness. In more specific contracts parties attempt to explicitly state, at the contracting date, how they would handle/resolve various situations that might occur in the future. For instance, the contract might specify the price determination process (e.g. Crocker and Masten 1991; Goldberg and Erickson 1987) or specify the kinds of adjustment procedures to used (e.g. Bajari, McMillan and Tadelis 2008). Given the difficulty of elucidating future contingencies and the costs of constructing detailed contracts, this is not a trivial task.

Governance logic dictates that the appropriate level of contract specificity is one that balances two countervailing factors: The ex ante costs of drafting contracts that are more specific with the ex post costs of keeping contract terms open (Crocker and Masten 1991; Ghosh and John 2005). The ex ante costs include the costs borne in managerial time and effort in searching for information, projecting future scenarios, identifying feasible contingencies, and negotiating mutually acceptable solutions. The ex post costs are the problems encountered in the execution and implementation stages (e.g., delay in delivery, improper specification, etc). Crafting more detailed clauses that clarify the roles and responsibilities reduces potential misunderstandings and safeguard investments by discouraging the counter-party from engaging in ex post opportunistic re-negotiations (Wathne and Heide 2000). In contrast, keeping contract terms open enables ex post value-enhancing adjustments but also gives the counter-party an opportunity to exploit unspecified loopholes that lead to higher ex post problems.

This inter-play between ex ante and ex post costs is the key design issue when parties choose the level of contract specificity. For simple transactions (e.g., purchase of X units of a PC or a standardized software), the ex post trading hazards are likely to be low, reducing the value of writing more specific contracts. The upfront costs of writing precise terms are also likely to be trivial. In 
contrast, for more complex transactions (e.g., purchase of customized hardware/software that create lock-in), far-sighted parties anticipating higher levels of ex post problems are likely to write more detailed clauses that specify contingencies, roles and responsibilities. The upfront costs of constructing such complex contracts, however, are also likely to be high. The desired level of specificity, then, is one where the contracting party trades-off between the costs of specifying more contingencies with the gains from safeguarding against potential problems. Said differently, for a given exogenous level of transactional attributes, the level of contract specificity and the expected ex ante and ex post costs are joint outcomes. We now proceed to apply this schema to our context of IT contracts.

\section{The IT Buying Context and the Specificity of IT contracts}

Our context pertains to procurement contracts for IT hardware/software between buying firms that operate in a wide range of industry sectors, and their respective IT vendor. ${ }^{2}$ This context is interesting for four reasons. First, customer firms, regardless of the industry sector they compete in, use IT products and services in a wide variety of administrative/operational activities to enhance productivity and effectiveness. Second, these products have a "multiplier effect". Specifically, (a) if the product is flawed, unable to operate per requirements, or incompatible with other IT systems on the customer's premises, or (b) if post-sales implementation issues like adjustments to product configurations on-site, installation, and service support are improper, the opportunity costs to the customer of lost productivity can be substantial and larger than the capitalized value of the product. ${ }^{3}$

Third, IT product markets are characterized by significant inter-generational improvement in hardware/software and proprietary technologies that not only add considerable ambiguity in assessing their quality but also induce potential lock-in (e.g. Weiss and Heide 1993) and require extensive coordination between the parties. Finally, compared to on-going supply relationships that have a series of recurring transactions (e.g., manufacturer-component supplier, manufacturer-distributor/retailer) which permit the evolution of relational norms to support exchanges, capital IT purchases of rapidly obsolescing products are lumpier, or discrete, in nature with the focus being "to ensure that 
expectations are realized" in that specific transaction (Kern and Willcocks 2001). Under these circumstances, one can expect managers to expend considerable time and effort in choosing products and governing those transactions with appropriate contract terms.

We use "contract specificity" to indicate the extent to which contract terms with respect to a) technical specifications of the product, b) implementation procedures, c) financial and legal considerations, and d) overall contractual features, are specified in detail ex ante. Our measure taps into the buying firm's perspective on the contract governing the exchange and is similar to one used in previous research on relational contracting (e.g. Lusch and Brown 1996; Wuyts and Geyskens 2005). A high level of specificity means that contract terms with respect to the four features are more detailed and explicit. Likewise, a low level of specificity means that these terms are less detailed and explicit.

Safeguarding Buyer Lock-In: We define buyer lock-in as the difficulty faced by the buyer in switching or replacing products or suppliers (Dutta et al. 1995). Such lock-in gets generated when buyers make supplier-specific investments (Weiss and Anderson 1992). For instance, in IT markets, buying firms often purchase a vendor's products that are unique and embody proprietary technologies (John, Weiss, and Dutta 1999; Heide and Weiss 1995). Likewise, specialized human assets also create lock-in because the buyer's personnel have to develop specialized skills and knowledge to derive productive output from that vendor's product (Williamson 1985). Lock-in implies higher switching costs and increases the hazards of opportunistic behavior by the vendor (Houston and Johnson 2000). For instance, knowing that the buyer cannot easily switch to another vendor, the focal supplier might demand price or delivery concessions or not be prompt enough in providing post-sales implementation support. Farsighted buyers, realizing their vulnerability under higher lock-in, expend effort to draft formal contract terms that spell out roles and responsibilities in specific details and discourage rentdissipating effort (Stump and Heide 1996); in effect, these contracts will be less flexible to provide better safeguards (Heide 1994). Drafting contracts with specific details, in turn, will require costly investment in time and managerial resources for expounding the contingencies 
and constructing effective rules to manage those contingencies. Overall, we hypothesize:

H1: The greater the buyer lock-in, the more specific the contract, all else equal.

Managing Transaction Complexity: IT transactions often involve purchase of hardware, software, and services that are architecturally inter-dependent (Bensaou and Anderson 1999) and hence require coordination during the design and implementation stages. We define transaction complexity as the need for coordination between the parties to produce the desired final product or service. Higher levels of transaction complexity create three types of transactional hazards. First, it introduces uncertainty about the cause of product failure making it difficult to apportion blame (Anderson and Dekker 2005; Masten and Snyder 1993) and leads to costly renegotiations (Crocker and Masten 1991). Second, it makes it more difficult to generate a mutually agreeable "meeting of the minds", expectations, and responsibilities (Lusch and Brown 1996; Stump and Heide 1996). Third, it increases implementation problems ex post, especially if appropriate governance structures that detail the desired level of coordination and communication between the parties are not set (Sanchez and Mahoney 1996). For instance, ex post adjustments are likely to be higher, the more the number of hardware, software, or service products procured under the contract. More specific contracts that detail the implementation procedures or financial and legal obligations of the parties then serve as a form of vertical control (Klein 1989) that mitigate the hazards arising from transaction complexity. In turn, higher managerial effort has to be expended in drafting such details. Hence, we posit:

$\mathrm{H} 2$ : The greater the transaction complexity, the more specific the contract, all else equal. Managing Measurement Ambiguity: We define measurement ambiguity as the difficulty of defining ex ante and verifying ex post the products procured in the contract (Anderson and Dekker 2005). Given bounded rationality, greater ambiguity in measurement makes it more difficult to assess the contractual compliance by the vendor (Heide and John 1990; Stump and Heide 1996). This in turn is likely to increase the buyer's hazards. For instance, the vendor might shirk and not provide the expected level of implementation and post sales service support (Houston and Johnson 2000) or might 
deliver products that do not match buyer requirements leading to mal-adaptation costs and productivity losses (Wathne and Heide 2000). In such circumstances, far-sighted buyers would seek to exert control (Weiss and Anderson 1992) and construct more detailed contract terms. This need to manage transaction hazards through more comprehensive contracting, however, is countervailed by an increasing difficulty in explicating appropriate contractual provisions (Rindfleisch and Heide 1997); hence, the ex ante effort in crafting more specific contracts should also increase with measurement ambiguity (Saussier 2000). Overall, we hypothesize:

H3: The greater the measurement ambiguity, the more specific the contract, all else equal.

\section{Performance Implications}

We now turn to investigate the implications of contract specificity on two dimensions of performance.

The first, ex post transaction costs, refers to the degree to which the buying firm encountered problems in the contract execution and implementation stage. These problems, among others, include (a) price exceeding expectations, (b) deliveries going beyond schedule, (c) products/services being incomplete, incompatible with other IT products/systems, or unable to perform per requirements, (d) installation and on-site customization being inappropriate or sloppy and (e) inadequate service support. Buying firms would clearly want to reduce these problems to prevent disruption of their operational activities. The second dimension, ex ante contracting costs, refers to the managerial effort expended at the contracting stage to detail the terms and provisions in the contract. These costs not only include the nominal cost of writing the agreement but also the costs of specifying their needs, seeking information, and negotiating with the counter-party (Saussier 2000). Managers at buying firms would be cognizant of not expending unnecessary effort in detailing these contracts.

$\mathrm{H} 1-\mathrm{H} 3$ predict how shifts in attributes influence the level of contract specificity. Critically, this expected level of specificity is endogenously chosen to jointly account for both the ex ante costs and ex post problems for a given level of transactional attributes. Hence, to understand the performance effects of this choice, it would be misleading to posit a priori a direct relationship 
between the observed level of contract specificity and performance without accounting for the transactional attributes (Hamilton and Nickerson 2003; Shaver 1998). Note that, for a variety of factors including corporate-specific culture/policies, strategic thinking, managerial experience, managerial inertia and/or myopia, and random noise, the observed level could be different from the expected level of contract specificity. ${ }^{4}$ Our primary goal here is not to ask why these deviations exist but to investigate the impact of these deviations on exchange performance.

We argue that systematic deviation between the expected and observed levels of contract specificity is an important determinant of performance. In particular, when the observed level is lower than expected (i.e. the deviation is negative), the ex post costs would be magnified because the lower than expected level of details increases the likelihood of genuine misunderstanding between the parties on contract terms and procedures as well as of partner opportunism (Heide 1994; Wuyts and Geyskens 2005). In effect, the transaction is under-coordinated and under-safeguarded. In contrast, when the observed level is higher than expected (i.e. the deviation is positive), the ex post costs are likely to be lower because such contracts are more likely to be enforced by third parties (e.g., courts) which increases the incentives to abide by the terms of the contract. Such over-coordinated and oversafeguarded transactions are also likely to have a more detailed agreement on the responsibilities and expectations of the parties (Lusch and Brown 1996). Hence, we hypothesize:

H4: All else equal, the more positive (negative) the difference between the observed and expected level of contract specificity, the lower (higher) the ex post transaction costs.

The impact of such deviations will be the opposite on the ex ante contracting costs. In particular, when the observed level is lower than the expected level (i.e. the deviation is negative), the out-of-pocket managerial contracting costs are likely to be lower because buyer-managers would have expended lower effort in constructing the relevant contractual details. In contrast, when the observed level is higher than the expected level (i.e. the deviation is positive), contracts will be over-specified and the ex ante costs of writing more detailed contractual specifications are likely to increase because 
of higher ink, search, and negotiation costs. Hence, we propose the following hypothesis:

H5: All else equal, the more positive (negative) the difference between the observed and expected level of contract specificity, the higher (lower) the ex ante contracting costs.

\section{Control Variables}

A variety of factors may influence the level of contract specificity. We include three prominent ones as control variables. First, larger sized transactions are likely to exacerbate the hazards faced by the buyer; hence, we expect buyers to draft more specific contracts as transaction size increases (Heide 1994). Second, frequent prior interactions are likely to have fostered elements of trust that reduce the need to draft contractual safeguards; hence, we expect contracts to be less specific as frequency of prior interaction increases. Finally, products that are important from the buyer's operational and profitability point of view are likely to be procured under contracts that are more specific.

\section{METHOD}

\section{Research Context}

We test our hypotheses using the "External Management of Automation" dataset available at the Steinmetz Archive (Batenburg and Raub 1995). This data was collected by the department of sociology at Utrecht University, The Netherlands, with the goal of examining how buying firms manage their IT transactions (Buskens et al. 2000). The unit of analysis is a transaction between buying firms in the Netherlands and vendors of IT products and services.

The sampling frame was obtained from Directview/Cendris, a marketing research firm specializing in IT that annually contacts all companies in their database to maintain up-to-date records. This includes about $80 \%$ of small and medium-sized Dutch firms. The study used a $3 * 3 * 4$ stratified sampling design based on three dimensions: 3 levels of network embeddedness of the organization (weak, middle, and strong), 3 levels of buyer IT expertise (low, middle, and high), and 4 types of product groups (standard hardware, standard software, complex hardware, complex software). The study also used two additional selection criteria. First, they randomly selected at least 15 cases for each 
of the 36 cells mentioned above. Second, they deliberately oversampled firms that purchased more innovative and complex products. Oversampling increases the precision of the estimates for complex hardware/software transactions but has the disadvantage that sample descriptive statistics might not be representative of the population.

This procedure resulted in a list of 1,798 companies that were contacted by phone. A key informant approach was used to identify the individual responsible for these IT transactions. These individuals were then asked to identify an IT transaction with an independent vendor that met the aforementioned criterion of transaction complexity. Care was taken to ascertain that the key informant was sufficiently knowledgeable about the transaction. This procedure resulted in 1,325 usable organizations that were the subsequent focus of the study.

These key informants were then administered a survey instrument with the specific transaction in mind. 788 individuals agreed to participate in the survey resulting in a response rate of 59\% (788/1325). This response rate compares very favorably with other studies conducted in business-tobusiness contexts. At 547 companies, the survey was administered on-site whereas in the remaining 241 companies, it was administered using a mail survey. About $95 \%$ of the informants had 10 years of tenure at the company they reported on and about 10 years of experience in IT. This suggests a high level of global and specific competence of these informants. In an additional 183 cases, these informants were willing to answer a separate, independent survey on a different IT transaction. In all, this resulted in 971 observations. The buying firms belonged to a broad spectrum of industries, such as logistics, parts production, and wholesaling. More than $95 \%$ of the responses in the sample came from companies that had 66 to 100 full-time employees.

Response bias was formally assessed by the comparing response rates across industries and regions and by comparing respondents and non-respondents on the satisfaction they reported with their respective transactions. ${ }^{5}$ The difference in average satisfaction between respondents ( 6.9 on a 10 -point scale) and non-respondents (6.8) was statistically insignificant suggesting that non-response bias was 
not a major concern with the data. Second, no systematic patterns of differences were observed for different methods of data collection methods (on-site versus mail). Finally, the original stratification criteria were matched with the post hoc data to check the original design goals. The results indicate that the stratification goals were reached.

\section{Measures}

Appendix 1 provides the measurement scales in our study. Table 1 provides the descriptive statistics and some sample descriptors that shows the heterogeneity in our sample. Note that we use a combination of perceptual and grounded measures that reflect verifiable information. Below, we start with presenting the details on our endogenous variables.

-Table 1 about here

\section{Endogenous variables:}

Contract specificity: Contract specificity refers to the degree to which contract terms with respect to a) technical specifications of the product, b) implementation procedures, c) financial and legal considerations, and d) overall contractual features, are specified in detail in the contract ex ante. This measure is similar to those used by Lusch and Brown (1996) and Wuyts and Geyskens (2005) and provides the buyer's perspective on the level to which contract terms are well specified.

Ex post transaction costs: Ex post transaction costs are defined as the extent to which 11 problems (details in Appendix 1) were encountered by the buying firm ex post. Different types of ex post problems can surface in different transactions; hence, we construct a formative scale and summate the perceptual severity of the problem for each of the 11 items to generate an overall measure of these costs. Higher values would indicate that buyers faced higher levels of these ex-post costs.

Ex ante contracting costs: We define ex ante contracting costs as the number of managerial days that were spent on crafting the details of the contracts. The range of days spent on writing contracts ranges from less than a day to 200 days; hence, we used a logarithmic transformation of the raw measure in our analysis. 


\section{Exogenous variables:}

Buyer lock-in: Buyer lock-in is defined as the difficulty faced by the buyer in switching or replacing products or suppliers (Dutta et al. 1995). We measure it using a four-item scale that looks at the magnitude of costs, in time and money, the buyer would incur if the focal supplier's product were to be replaced. These damages and costs relate to purchasing another product, (re) training the buyer's personnel, new data and information entry, and idle production.

Measurement ambiguity: This measure refers to the degree of difficulty faced by the buyer in defining ex ante and verifying ex post the products/services procured under this contract. We use a three-item scale that taps into the difficulty faced by the buyer organization in judging the quality of the product/service at the time of delivery, in comparing the focal product/service with other products, and in judging the price/quality ratio of potential suppliers' products/services.

Transaction complexity: This construct refers to the extent of coordination required between the buyer and seller to satisfactorily produce the desired final product/service. We use two separate indicators to measure this construct. The first indicator is a simple count of the number of products and services covered under the focal contract. As we see in Appendix 1, there were 18 potential types of products and services that could be procured in a single contract. This measure hence taps into the scope of the transaction with higher scope being indicative of higher transaction complexity and need for enhanced coordination. The second indicator rates the complexity of products and services and hence represents increasing demands for coordination and interaction between the buyer and seller. To construct this scale, the 18 types of products were assigned to five categories by two experts. Category one represents the least need for coordination and interaction whereas category five the most. Category one, two, and three represent standard and more advanced products and services respectively. Category four represents specialized, and category 5 tailored, products or services. If multiple products were included in the same transaction, the highest category score was used to rate the complexity. The two indicators of transaction complexity, namely the count of products and the ratings measure correlate 
with each other significantly $(\mathrm{R}=.68)$; yet the fact that the correlation is far from unity provides some evidence that they tap into different aspects of complexity. We then sum these two items to create our final measure that taps into increasing complexity in transactions. ${ }^{6}$

Transaction size: Transaction price refers to the original price in the contract excluding any follow-up work that might have been subsequently performed. Informants had to choose between five categories of costs that were measured in Dutch Guilders. In U.S. dollars, the approximate price categories are less than $\$ 15,000$, between $\$ 15,000$ and $\$ 30,000$, between $\$ 30,000$ and $\$ 60,000$, between $\$ 60,000$ and $\$ 120,000$, and more than $\$ 120,000$.

Frequency of prior interaction: This single item, five-point Likert scale measures how frequently the buyer has done business with the supplier prior to the focal transaction.

Importance of transaction: This two-item, five-point Likert scale reflects the value of the transacted products or services to the buyer. The two items measure the perceptions of the buyer on the importance of the products/services to the automation and profitability of the buying organization.

\section{Measurement Validity}

We used confirmatory factor analysis to assess unidimensionality and discriminant validity of our multi-item constructs and estimated a single model with three variables: transaction complexity, lockin, and measurement ambiguity. The model fit statistics were: $\chi^{2}(39)=214.65$; root mean squared error of approximation $(\mathrm{RMSEA})=.067 ; \mathrm{CFI}=.96 ; \mathrm{IFI}=.96 ; \mathrm{NFI}=.95$ suggesting a reasonably well fitting measurement model. Furthermore, all the factor loadings were significant at $\mathrm{p}<.01$ level; providing evidence of convergent validity. We also conducted Harman's one factor test (Podsakoff and Organ 1986) to determine if one factor could adequately account for the variance. The model $\left(\chi^{2}(45)=\right.$ 2428.63, $\mathrm{RMSEA}=.27, \mathrm{CFI}=.45, \mathrm{IFI}=.46, \mathrm{NFI}=.45)$ falls below the acceptable levels of fit and suggests that the observed variance cannot be explained by one underlying factor. Furthermore, since many of the measures can be objectively verified (i.e. not perceptual measures), we expected a priori that any possible common method bias would be minimal. 
We used Fornell and Larcker's (1981) procedure to assess discriminant validity. Specifically, we calculated the average variance extracted and compared the square root of this to the inter-construct correlations. Table 1 shows that the square root of the average variances extracted, where they could be calculated, exceeds the inter-construct correlations suggesting that each construct shares more variance with its own measures than with other constructs. The reliability of the scales, calculated using Cronbach's Alpha, were found to be adequate. These measures are provided in Appendix 1.

\section{Contract Specificity Analysis}

Our dataset contains observations from buying organizations that provided data on one or two separate IT transactions. Given this, we conduct two separate sets of analysis to show robustness. In the first, we make use of the entire dataset to estimate the contract specificity choice and subsequent performance effects. In the second, we estimate the contract specificity and performance effects using data from firms that report on two transactions. This enables us to account for firm-specific effects and provides a stronger test of our hypotheses. We first report on the analysis for the whole dataset below. The latter analysis is reported in a separate sub-section on "controlling for firm-specific effects".

Given the presence of one and two data points per firms, we used Feasible Generalized Least Squares (FGLS) as our estimation technique. FGLS enables the clustering of data using a firm identification variable (in our case, firms with either 1 or 2 responses) and accounts for the intercorrelation between multiple observations per firm. It also estimates the error structure (Beck and Katz 1995; Wooldridge 2001), making the results less sensitive to unexpected error distributions, including potential heteroskedasticity. Operationally, we used the XTGLS module in STATA 9.2 to implement FGLS and used a firm identification variable to cluster organizations that provided data on two transactions. For firms that provide two data-points, the data collection process involved an informant who provided data on one transaction first followed by data on a second, separate, transaction. This may give rise to various issues analogous to classical within-subject designs such as practice, carryover effects, or genuine differences between within-subject observations. Therefore, we include a 
dummy to identify the second observation for each firm as a control for possible effects that may make such repeat transactions different. In essence, we deal with issues related to firm-specific effects through the dummy while simultaneously taking into account the clustered nature of our data. The model used to estimate contract specificity is shown in Equation 1 below.

(1) Contract specificity $=\beta_{0}+\beta_{1} *$ Lock-in $+\beta_{2} *$ Transaction complexity $+\beta_{3} *$ Measurement ambiguity $+\beta_{4} *$ Transaction size $+\beta_{5} *$ Frequency of prior interaction $+\beta_{6} *$ Importance of transaction $+\beta_{7} *$ Dummy $+\eta$

Model 1 in Table 2 shows the results for our core predictors. We find that consistent with $\mathrm{H} 1$ and $\mathrm{H} 2$, contracts become more specific as buyer lock-in with the vendor's product/technology increases $(\beta=.187, \mathrm{p}<.01)$ and as transaction complexity increases $(\beta=.141, \mathrm{p}<.01)$. In contrast, the results were opposite to our prediction in $\mathrm{H} 3$; contracts become less specific as it becomes more difficult to evaluate the product ex ante $(\beta=-.109, \mathrm{p}<.05)$. One potential reason could be that the costs faced by the buying firms in evaluating and comparing product features and writing more comprehensive contracts to assure value delivery ex post are higher than the hazards posed from less detailed contracts. Model 2 provides the estimates for our full model as specified in equation 1 where we add four control variables: size of transaction, frequency of prior interaction, importance of the transaction, and a dummy variable indicating whether the data is from a buying firm that provided one versus two data points. The core variables again remain strongly significant and directionally consistent. In addition, as the size of transaction increase, contracts become more specific $(\beta=.481, \mathrm{p}$ $<.01)$. The impact of the dummy is marginally significant $(\beta=.587, \mathrm{p}<.10)$ suggesting that firms providing data on two transactions used more specific contracts than firms providing data on one transaction did. The effect of other control variables was insignificant. ${ }^{7}$

$$
\text { -Table } 2 \text { about here- }
$$

\section{Performance Analysis}

As contract specificity is endogenous to variations in transaction hazards, we need to account for this 
endogeneity while assessing the performance implications. ${ }^{8}$ To confirm this theoretical rationale, we first establish empirically whether endogeneity is an issue in our context by conducting the standard Durbin-Wu-Hausman test (Davidson and MacKinnon 1993). Specifically, we computed the residual, $\hat{\eta}$, from equation 1 (estimated from Table 2, Model 2) and used this residual as an additional regressor in the two cost equations - ex post transaction and ex ante contracting costs - after incorporating all the independent variables in Model 2, Table 2, minus the importance of transaction, for identification purposes. The parameter estimate for the residual was highly significant $(\mathrm{p}<.01)$ in both cost equations, clearly indicating that contract specificity is endogenous in our setting.

Having established the existence of endogeneity, we now use two different approaches to test H4 and H5 while simultaneously accounting for the endogeneity. The first approach, which we call the whole residual analysis, tests whether the cost impact of the overall deviations from expected contract specificity is consistent with $\mathrm{H} 4$ and $\mathrm{H} 5$. The second approach, which we call the split residual analysis, tests whether cost impact of positive and negative deviations are, independently and separately, consistent with the stated hypotheses. We turn to the task below.

Whole Residual Analysis: This technique was proposed by Garen $(1984 ; 1988)$ to correct for selection bias and is especially useful when lack of "good" instrumental variables makes standard IV approaches problematic. The Garen procedure is a modification of the Heckman-Lee two-stage discrete choice estimator (Heckman 1979) and specifically accounts for the continuous nature of our selection variable - contract specificity. Accordingly, we first obtain the residual from equation $1(\hat{\eta})$ and then compute the interaction term $\hat{\eta}$ x Contract Specificity. The coefficient of the $\hat{\eta}$ term is of key interest to us because it provides the direction for the selection bias. Specifically, a negative coefficient would suggest that increases in $\hat{\eta}$ decreases costs and vice versa. The $\hat{\eta}$ x Contract Specificity term accounts for unobserved heterogeneity over the range of the continuous selection variable. The residual and the interaction term, along with the selection variable and its interactions with key exogenous variables 
from stage 1, are then used as regressors in the performance analysis to implement the Garen procedure. We used FGLS to estimate each of our two performance/cost equations given below.

(2) Ex post Transaction Costs $=\gamma_{0}+\gamma_{1} *$ Contract Specificity $+\gamma_{2} * \hat{\eta}+\gamma_{3}^{*} \hat{\eta} *$ Contract Specificity + $\gamma_{4} *$ Lock-in $*$ Contract Specificity $+\gamma_{5}^{*}$ Transaction Complexity $*$ Contract Specificity $+\gamma_{6} *$ Measurement ambiguity * Contract Specificity $+\tau$

(3) Ex ante Contracting Costs $=\theta_{0}+\theta_{1} *$ Contract Specificity $+\theta_{2} * \hat{\eta}+\theta_{3} * \hat{\eta} *$ Contract Specificity $+\theta_{4} *$ Lock-in $*$ Contract Specificity $+\theta_{5} *$ Transaction Complexity $*$ Contract Specificity $+\theta_{6} *$ Measurement ambiguity * Contract Specificity $+\pi$

Model 1 in Table 3 shows the results for ex post transaction costs. The coefficient of $\hat{\eta}$ is negative and significant $(\beta=-0.284, \mathrm{p}<0.01)$, showing that contracts that were more specific than expected lowered ex post transaction costs and vice versa. The coefficient for the term $\hat{\eta}$ x Contract Specificity term is significant and negative $(\beta=-0.122, \mathrm{p}<0.05)$. As would be expected, the main effect of the endogenous, predicted level of contract specificity (that accounts for lock-in, transaction complexity, and measurement ambiguity) is positive and significant $(\beta=1.512, \mathrm{p}<0.01)$. All other effects in Model 1 are insignificant.

-Table 3 about here-

Model 3 in Table 3 show the results for ex ante contracting costs. Here we find that the coefficient of $\hat{\eta}$ is positive and significant $(\beta=0.014, \mathrm{p}<0.01)$ indicating that contracts that were more specific than expected increased ex ante contracting costs and vice versa. The coefficient for the $\hat{\eta} \times$ Contract Specificity term $(\beta=0.006, \mathrm{p}>0.10)$ is insignificant. We also find that per expectations, higher levels of endogenous, predicted level of contract specificity leads to higher ex ante contracting costs $(\beta=0.223, p<0.01)$. Finally, the interaction effect of transaction complexity and contract specificity is the only other significant effect $(\beta=-0.011, \mathrm{p}<0.01)$. 
For both models, we also used the Ramsey RESET test (Ramsey 1969; Wooldridge 2001) to investigate the presence of non-linearity in the effect of $\hat{\eta}$ on costs. The results $(\mathrm{p}>0.10)$ indicate that the presence of non-linearity is unlikely.

Split Residual Analysis: Even though the RESET test shows no evidence of non-linearity using the overall residual, there might exist some asymmetries if the cost impact of positive and negative deviations is estimated separately. This also provides an independent test for H4 and H5. To do so, we use a technique used in previous marketing (e.g., Anderson and Sullivan 1993; Zeithaml et al 1996) and organizational studies (e.g., Berkowitz et al 2006; Rosen 2004). Specifically, if the residual from the contract specificity estimation (Model 2 in Table 2) for a given observation is $\eta_{i}$, we define and construct positive and negative residuals as follows:

Negative $=\left|\eta_{i}\right|$ if $\eta_{i}<0$, else 0 and Positive $=\eta_{i}$ if $\eta_{i}>0$, else 0 .

We then separately estimate equation 4 for each of the two cost measures using these split residuals. We use the predicted level of contract specificity to proxy for the transaction attributes and include the interaction terms.

4) Ex ante/Ex post Costs $=a_{0}+a_{1} *$ Positive $+a_{2} *$ Negative $+\alpha_{3} *$ Contract Specificity $+\alpha_{4} *$ Lock-in

$*$ Contract Specificity $+\alpha_{5} *$ Transaction Complexity $*$ Contract Specificity $+\alpha_{6} *$ Measurement ambiguity $*$ Contract Specificity $+a_{7} *$ Dummy $+\pi$

Model 2 in Table 3 shows the results for ex post costs. Using a one-tailed test for our directional hypotheses, $\mathrm{H} 4$ and H5, we find that as hypothesized, the impact of Positive is negative and significant $(\beta=-0.404, \mathrm{p}<0.01)$, suggesting that contracts that are more specific than expected lowered ex post transaction costs. In contrast, the impact of Negative is not significant $(\beta=0.131, \mathrm{p}>$ 0.10). Likewise, model 4 in Table 3 provides the results for ex ante contracting costs. Using a onetailed test we find that the impact of both Positive $(\beta=0.016, \mathrm{p}<0.05)$ and Negative $(\beta=-0.012, \mathrm{p}<$ 
0.10) to be directionally consistent with the hypotheses and significant suggesting that contracts that were more (less) specific than expected had marginally higher (lower) expenditure of managerial effort. Further, consistent with the findings in the whole residual analysis, the impact of the expected level of contract specificity is strongly significant and positive for both cost measures.

In sum, using two different approaches to handle endogeneity - the whole and split residual analysis - we find that results are generally consistent with expectations. They also provide two key insights on governance costs. First, in line with past findings (Pilling, Crosby and Jackson 1994), more complex transactions (that are supported by more specific contracts) have higher ex ante and ex post costs. Deviating from the expected level of governance, however, leads to a crucial divergence in the impact on the two cost metrics. In particular, contracts that are more (less) specific than expected lowered (raised) ex post transaction problems but raised (lowered) ex ante contracting costs. These subtle findings are a critical element of the governance logic espoused in TCE.

\section{Controlling for Firm-Specific Effects}

Recall that we have a substantial number of buying firms that provided data on two IT transactions. Here, we assess the robustness of our results by explicitly accounting for firm-specific heterogeneity using data obtained from this sub-sample of firms that provided two observations. To capitalize on the strength of this data, we first constructed a "balanced panel" with information on all variables for both observations of each buying firm. This provided us 210 (105 firms times 2) observations. We then estimated a set of random effects models using GLS (Greene 2003) using the Garen specification to explain the choice of contract specificity and the subsequent effects on ex ante and ex post costs. ${ }^{9}$ For each firm, the more recent of the two transactions was coded as the "Dummy for second observation" and introduced in these models. This helps us to investigate any systematic time-related effects. Equations 5, 6, and 7 show the specification for these models using the Garen (whole-residual) procedure.

(5) Contract specificity $=\beta_{0 i t}+\beta_{1 i t} *$ Lock-in $+\beta_{2 i t} *$ Transaction complexity $+\beta_{3 i t} *$ Measurement 
ambiguity $+\beta_{4 i t} *$ Transaction size $+\beta_{5 i t} *$ Frequency of prior interaction $+\beta_{6 i t} *$ Importance of transaction $+\beta_{7 i t} *$ Dummy for second observation $+\sigma_{u i+} \sigma_{e i t}$

(6) Ex post transaction costs $=\gamma_{0 i t}+\gamma_{1 i t} *$ Contract specificity $+\gamma_{2 i t} * \hat{\eta}+\gamma_{3 i t} * \hat{\eta} *$ Contract specificity $+\gamma_{4 i t} *$ Lock-in $*$ Contract specificity $+\gamma_{5 i t} *$ Transaction complexity $*$ Contract Specificity $+\gamma_{6 i t} *$ Measurement ambiguity $*$ Contract Specificity $+\gamma_{7 i t} *$ Dummy for second observation $+\sigma_{u i+} \sigma_{e i t}$

(7) Ex ante contracting costs $=\theta_{0 i t}+\theta_{1 i t} *$ Contract Specificity $+\theta_{2 i t} * \hat{\eta}+\theta_{3 i t} * \hat{\eta} *$ Contract specificity $+\theta_{4 i t} *$ Lock-in $*$ Contract specificity $+\theta_{5 i t} *$ Transaction complexity $*$ Contract specificity $+\theta_{6 i t} *$ Measurement ambiguity $*$ Contract specificity $+\theta_{7 i t}$ Dummy for second observation $+\sigma_{u i}+\sigma_{e i t}$

$\sigma_{u i}$ is the firm-specific error term (unobserved heterogeneity) and $\sigma_{e i t}$ is the model error with the $i$ and $t$ subscripts referring to the individual firms and the two measurement waves respectively. The intra-class correlation (the correlation of between-transactions communality for the same firm) is given by $\rho$ and calculated as $=\sigma_{\mathrm{u}}{ }^{2} /\left(\sigma_{\mathrm{u}}^{2}+\sigma_{\mathrm{e}}{ }^{2}\right)$.

Table 4 shows the results. The value of $\rho$ is quite significant for the contract specificity and ex ante costs equations suggesting strong firm-fixed effects. Overall, we again observe that buyers choose the level of contract specificity to mitigate hazards arising from safeguarding and adaptation problems. The coefficient for the dummy in the contract specificity equation $(\beta=0.859, \mathrm{p}<0.05)$ suggests that contracts were more specific for the more recent transaction. The cost effects again show evidence of selection bias and deviation effects that are consistent with previously reported results. The coefficient for $\hat{\eta}$ is negative and significant for ex post costs $(\beta=-0.311, \mathrm{p}<0.05)$ and positive and significant for ex ante costs $(\beta=0.026, \mathrm{p}<0.01)$. Overall, these results again suggest that the chosen level of contract specificity is a trade-off that balances ex ante contracting costs with ex post transaction problems. 


\section{DISCUSSION}

The foundation of governance theories is that for a given level of transactional attributes, governance levels are chosen to reflect a trade-off between the costs and benefits of setting up those structures. Deviating from this expected level, that accounts for transactional attributes, should then reveal a distinct pattern of effects on two counter-balancing dimensions of costs - ex ante contracting costs and ex post transaction problems. An analysis of micro-level details in IT contracts provides results consistent with this subtle but key principle. The results hold even after we control for unobserved firm-specific heterogeneity. We consider the research and managerial implications in turn.

\section{Implications for Research}

Our deviation-based joint analysis makes several important contributions. First, we provide the first explicit demonstration that ex ante contracting costs can prevent parties from seeking governance arrangements that lower ex post transaction costs. Consistent with theory (Williamson 1991) and past evidence (Pilling, Crosby, and Jackson 1994) we find that both ex ante and ex post costs go up as transactions become more complex. However, after controlling for transactional attributes, we find a more discriminating result. In general we find that contracts that are more specific than expected have lower ex post costs but higher ex ante costs and vice versa.

Second, our joint analyses enhance our understanding on why parties choose a particular level of governance. For instance, using similar kind of deviation analysis, Rosen (2004) and Bercovitz et al. (2006) find that unexpectedly higher relational norms improve performance - the implication being that parties could have done better had they chosen to be even more relational. However, they ignore the cost of constructing those higher than expected norms. Similarly, Leiblein et al. (2002) find that misaligned hierarchical governance (make) when theory predicts contractual governance (buy) enhances technological performance; however, they too ignore the administrative costs of internalizing the transaction. These studies did not find significant effects for less than expected levels of governance; hence, their results suggest a tantalizing conclusion: Only over-coordinated governance 
structures are more valuable vis-à-vis their theory-predicted levels. This begs the question: Why then would any transaction be not over-coordinated? Our joint analysis of the tension between the costs and benefits of contracting reintroduces the basic symmetry that is consistent with TCE: Both overcoordinated and under-coordinated governance structures have counter-balancing costs and benefits vis-à-vis their theory-predicted levels, providing a rationale for why contracting parties might not universally over or under-coordinate. We believe, our results make a cogent argument for evaluating such governance misalignment effects on multiple dimensions of performance; especially those that can be theoretically predicted to counter-balance each other.

Third, our data shows the problem in directly comparing the costs without accounting for the role of contracts and transaction attributes. To wit, consider a seemingly reasonable conjecture that time and effort spend in writing more precise contracts would lower ex post costs. Table 1, however, shows that the correlation between the two costs is significant and positive $(0.231)$. This may seem anomalous; yet is as per expectations if we consider that contract specificity and these two costs are jointly determined. In particular, when transactions are simple, not only the ex post costs but also the upfront costs of writing precise terms are low and the value of contracts is quite trivial. In contrast, when transactions become more hazardous (higher lock-in, complexity, etc.), ex post problems are likely to be higher and far-sighted firms, desiring to control these costs, would consciously put more effort and incur higher costs in constructing more detailed contracts. This logic is consistent with the entire pattern of observed correlations between attributes, contract specificity, ex ante and ex post costs in Table 1. In short, our results demonstrate the conceptual importance of correcting for endogeneity of contract form. Without accounting for this endogeneity, researchers would spuriously conclude that contracts that are more specific per se lead to higher ex ante and ex post costs.

Fourth, and relatedly, our results suggest that it is not necessarily true that an absolute level (high or low) of governance is better (or worse). For instance, past research (e.g., Zaheer, McEvily, and Perrone 1998) has reported that stronger norms of trustworthiness improve performance. However, 
this does not rule out the possibility that stronger than average norms in a particular instance might be insufficiently strong (for given attribute levels) and influence performance differently. Indeed Uzzi (1996) provides some evidence that performance declines beyond a certain level of relational norms; however, he does not specify why and where the crossover point comes into being. Consistent with Bercovitz et al. (2006), we argue that a fit analysis that accounts for transaction attributes is more appropriate to test the governance-performance link. How then do we reconcile these two approaches? We appeal for a more discriminating theoretical examination of what we mean by attributes and governance. In their analysis of inter-firm trust and performance, Gulati and Nickerson (2008) show the need to separate preexisting trust (an exogenous attribute of the exchange) from trust that is engineered to account for exchange hazards (an endogenous governance form). The former, exogenous trust could grease the wheels of friction and improve a relevant performance dimension (e.g., opportunism) regardless of other exchange hazards. In contrast, endogenous (calculative) trust should be amenable to the "fit" analysis. Formal contracts too might have a preexisting disposition. Nordberg et al. (1996), for instance, note that by law, CERN - the European Laboratory for Particle Physics contracts are rigid, pre-designed policies that are not sensitive to variations in transactional hazards. We argue for a conceptual parsing of the exogenous attribute-type and endogenous governance-type effects of "nominal governance forms" for a better understanding on how firms organize their transactions to realize better performance.

Finally, even though addressing endogeneity concerns is not new (e.g., Anderson 1988), our approach based on the whole-residual technique (e.g., Garen 1984) and the split-residual technique (Anderson and Sullivan 1993) has received relatively less attention hitherto in organizational studies. We believe these approaches could be fruitfully applied in a variety of marketing and inter-firm contexts where soft relational or hard contractual structures are measured using a continuous metric. Do choices that deviate from theory predictions have adverse implications in these contexts? A systematic empirical analysis of these issues would give us a better understanding on the role of 
governance in exchange performance.

\section{Implications for Practice}

Consider the recent Wall Street Journal article that documents the Goldilocks dilemma faced by a company on how to strike the right balance between "too little" versus "too much" contracting for IT procurement (Barthelemy 2008). We pose as "Governance Value Engineers" (Gilson 1984) and argue that designing a contractual framework should not be a task delegated to lawyers alone. Rather, sales and purchasing managers need to understand how contract design support value-creating activities in inter-firm relationships like IT sourcing. Based on our results, we offer the following advice.

We start by asserting that buyer-managers need to be aware of the costs and benefits of striking loose versus rigid contract terms. Writing more detailed contracts enables managers to set goals, clarify expectations, lower misunderstandings, and reduce the counter-party's range of opportunistic behavior. Ex post implementation costs are hence likely to be lower. However, drafting contracts that are more detailed would also require valuable expenditure in managerial time and effort in searching for information, projecting scenarios, identifying feasible contingencies, and negotiating mutually acceptable solutions. In contrast, keeping contract terms open enables parties to make value-enhancing adjustments and is likely to foster trust because parties do not hold each other to precise terms of the contract; however, opportunistic counter-parties can exploit unspecified loopholes that lead to wasteful hold-up and renegotiations. We encourage managers to build an expertise in evaluating these contract design issues, as they would clearly help in constructing cost efficient yet effective contracts.

Furthermore, our framework argues that it is crucial for managers to understand the properties of the transaction under consideration. Transactions that involve high lock-in to the vendor's product, that are more complex, and those where a clear-cut criterion to evaluate the vendor's products is not available upfront are quite likely to generate implementation hazards for the buyer. Buyer managers should be aware that compared to simpler transactions, such inherently complex transactions will not only require valuable managerial time and effort in constructing contract terms but are also likely to 
have more problems in the contract execution stage. Constructing contracts that are de-coupled from the essential nature of the transaction are not likely to be effective. We suggest a three-step decision frame to address these issues.

First, managers need to assess the hazards posed by transactional attributes. If these hazards are low, managers need not expend effort in constructing complex, detailed contracts. On the other hand, if the transactional hazards are high managers need to be more selective because managing such transactions leads to higher ex ante and ex post costs. As such, managers need to balance both these costs with the value-added from entering into such transactions in the first place. For instance, they need to assess whether the improvements in productivity and cost-efficiency from procuring customized hardware/software configurations is worth the potential costs of managing these transactions. Second, if the value-added from productivity improvements are substantial, managers need to balance the ex ante versus ex post costs. For instance, depending on particularistic contexts, crafting "too rigid" contracts might be beneficial because reduction in the ex post implementation problems overcome the added managerial costs of writing these contracts in sufficient details. Crucially, the level of "rigidity" has to reflect the level of transactional hazards posed in the particularistic. In short, contract managers need to construct contracts that are not too costly to design, yet are specific enough to reduce hazards. Third, given that complex transactions require high management effort, it would be useful to build in realistic expectations. Projects involving the procurement of complex, customized products/services are likely to take time in "fixing the bugs"; hence, it is advisable that provisions be made for such slack.

Finally, our results show that prior interaction with vendors helps reduce the costs of contracting and buyer-managers need to consider it while choosing IT vendors. However, the impact of transactional attributes on cost holds even after we control for this frequency of prior interaction. This validates our core argument that contracts reflecting current conditions and properties are critical to the success of IT procurement because they help organize and set the expectations between the 
buyer and seller.

\section{Limitations}

Our research has several limitations. First, our results are context dependent and one has to exercise caution in generalizing our results and insights in other domains. Second, our study focuses on only

one form of governance structure, namely contract specificity and its antecedents and performance implications. It is conceivable that investigating other feasible governance structures might provide different results. Third, the use of secondary datasets to test complex theoretical models has its own limitations. For instance, our measures of lock-in and transaction complexity could have alternative interpretations, leading to potential issues with construct validity. Moreover, secondary datasets bring along other limitations such as the possible exclusion of important measures and typically an inability to go back to the original providers of the data to seek further information on measures.

Fourth, even though our results strongly suggest that buying firms do trade-off between these two costs while choosing their level of contract specificity, the explicit trade-off points are not obvious. An analysis of the actual monetary costs of writing contracts that are more specific and of ex post transaction problems would enable a direct assessment of the efficiency of contractual choices. Fifth, our archival dataset did not permit us to investigate other dimensions of performance. For instance, even though we show the ex ante costs and ex post hazards from lock-in, complexity, and measurement difficulty, the benefits that buying firms derive from supplier-specific investments (that create lock-in) or buying complex products that require intense coordination between the parties are not investigated in our tests. Hence, an equally important strategic question, viz. "Why do buying firms want hazardous transactions that increase their ex ante and ex post costs?" remains unanswered in our analysis. Finally, we look at our problem using data obtained from the buying organization. An analysis of vendor-side data might provide different results and insights. We hope that future studies will address these issues. 
TABLE 1: CORRELATIONS AND DESCRIPTIVE STATISTICS

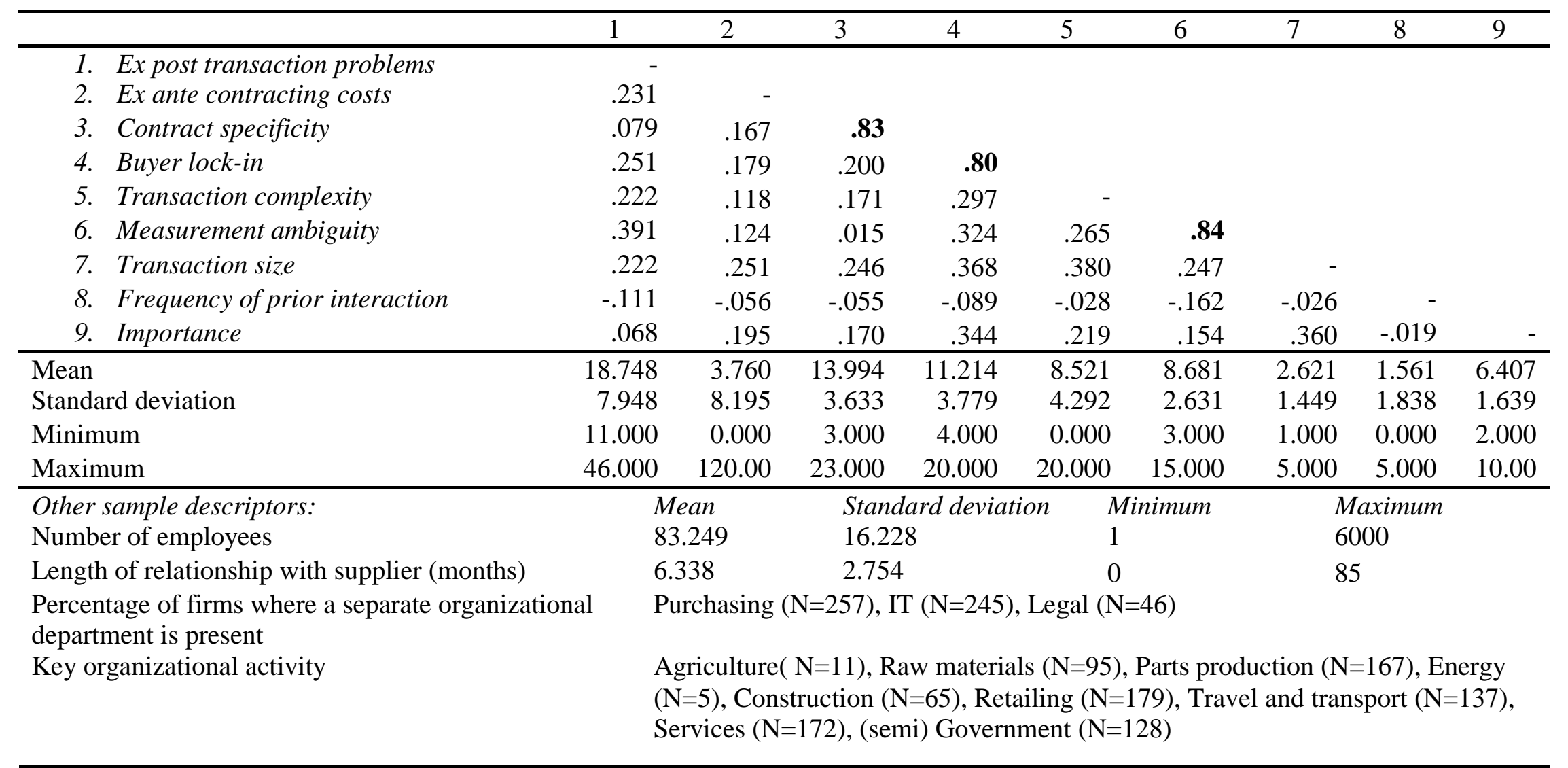

Correlation matrix for $\mathrm{N}=718$, Correlations over $|.08|$ are significant at $\mathrm{p}<.05,2$-sided

Values in bold on the diagonal are the square root of the average variances extracted. 


\section{TABLE 2: DETERMINANTS OF CONTRACT SPECIFICITY}

\begin{tabular}{|c|c|c|c|c|}
\hline \multirow{3}{*}{$\begin{array}{l}\text { Variables } \\
\text { Constant }\end{array}$} & \multicolumn{4}{|c|}{ Parameter estimates with standard errors in parentheses } \\
\hline & \multicolumn{2}{|c|}{$\begin{array}{c}\text { Contract specificity } \\
\text { (Model 1) }\end{array}$} & \multicolumn{2}{|c|}{$\begin{array}{c}\text { Contract specificity } \\
\text { (Model 2) }\end{array}$} \\
\hline & $11.511(.505)$ & $* * *$ & $10.941(.661)$ & $* * *$ \\
\hline Buyer lock-in ${ }^{a}$ & $.187(.037)$ & $* * *$ & $.134(.039)$ & $* * *$ \\
\hline Transaction complexity $^{a}$ & $.141(.031)$ & $* * *$ & $.089(.033)$ & $* * *$ \\
\hline Measurement ambiguity $^{a}$ & $-.109(.051)$ & $* *$ & $-.141(.052)$ & $* * *$ \\
\hline Transaction size & & & $.481(.103)$ & $* * *$ \\
\hline Frequency of prior interaction & & & $-.095(.070)$ & \\
\hline Importance of transaction & & & $.116(.086)$ & \\
\hline Dummy for second observation & $.481(.328)$ & & $.587(.329)$ & $*$ \\
\hline Model fit & Wald $\chi^{2}=63.14$ & & Wald $\chi^{2}=98$ & \\
\hline Estimation method & FGLS $(\mathrm{N}=835)$ & & FGLS $(\mathrm{N}=8$ & \\
\hline
\end{tabular}

$* \mathrm{p}<.10 ; * * \mathrm{p}<.05 ; * * * \mathrm{p}<.01$.

a: We use one-tailed tests for these posited directional hypotheses. 
TABLE 3: IMPACT ON EX POST TRANSACTION PROBLEMS AND EX ANTE

CONTRACTING COSTS

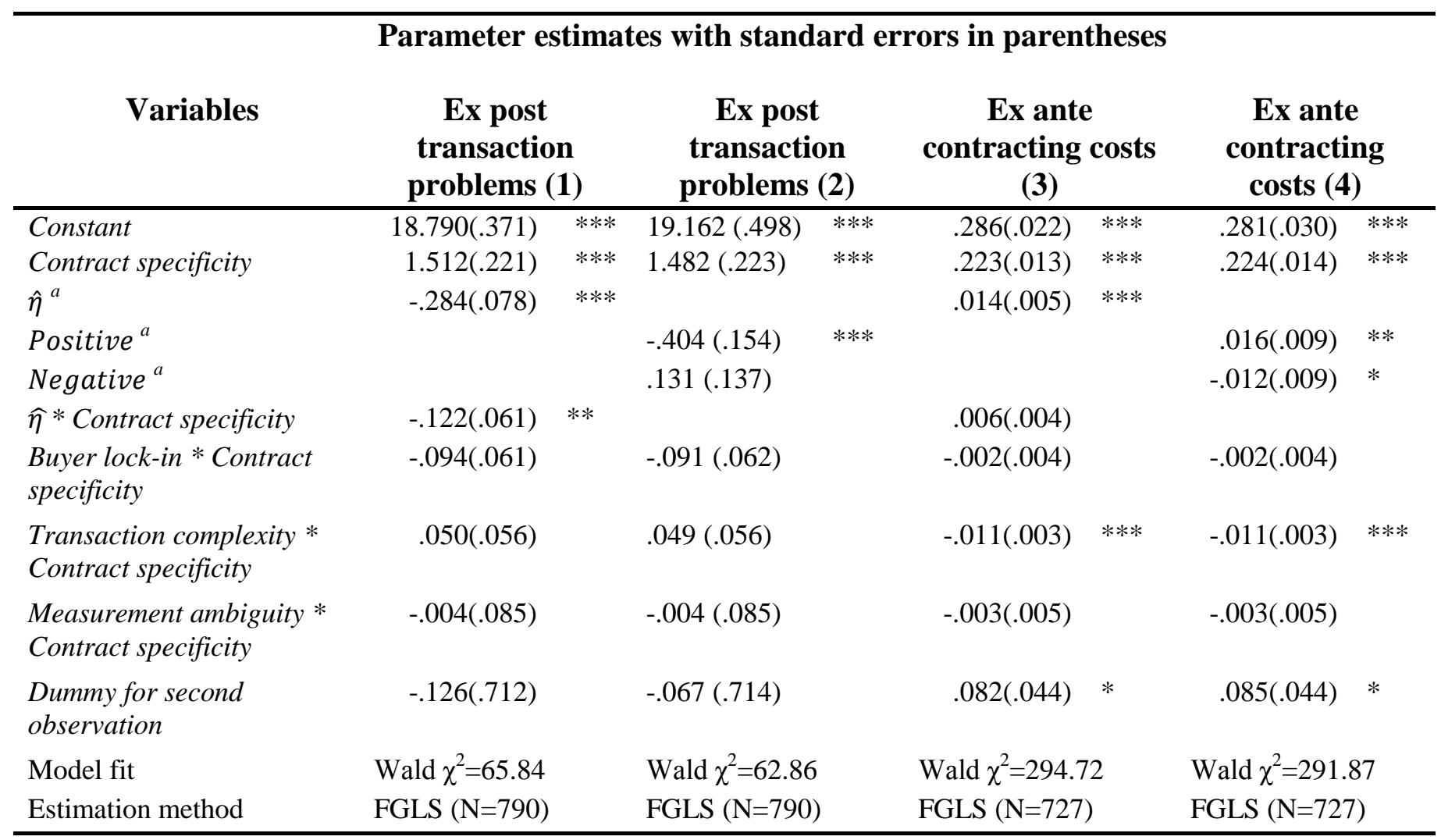

$* \mathrm{p}<.10 ; * * \mathrm{p}<.05 ; * * * \mathrm{p}<.01$

a: We use one-tailed tests for these posited directional hypotheses. 
TABLE 4: ACCOUNTING FOR UNOBSERVED FIRM-SPECIFIC HETEROGENEITY

Parameter estimates with standard errors in parentheses

Variables

Contract specificity (1)

Ex post

transaction costs (2)

Ex ante

contracting costs (3)

\begin{tabular}{|c|c|c|c|c|c|c|}
\hline Constant & $10.261(1.300)$ & $* * *$ & $18.585(.925)$ & *** & $.316(.049)$ & *** \\
\hline Contract specificity $^{a}$ & & & $.843(.434)$ & $* *$ & $.181(.022)$ & $* * *$ \\
\hline$\hat{\eta}^{a}$ & & & $-.311(.162)$ & $* *$ & $.026(.009)$ & $* * *$ \\
\hline$\widehat{\eta} *$ Contract specificity & & & $-.091(.113)$ & & $.006(.006)$ & \\
\hline Buyer lock-in * Contract specificity & & & $-.025(.123)$ & & $.007(.006)$ & \\
\hline $\begin{array}{l}\text { Transaction complexity } * \text { Contract } \\
\text { specificity }\end{array}$ & & & $.042(.104)$ & & $-.008(.005)$ & \\
\hline $\begin{array}{l}\text { Measurement ambiguity } * \text { Contract } \\
\text { specificity }\end{array}$ & & & $-.265(.153)$ & $*$ & $-.008(.008)$ & \\
\hline Buyer lock-in ${ }^{a}$ & $.093(.080)$ & & & & & \\
\hline Transaction complexity $^{a}$ & $.105(.061)$ & $* *$ & & & & \\
\hline Measurement ambiguity $^{a}$ & $-.139(.102)$ & $*$ & & & & \\
\hline Transaction size & $.524(.198)$ & $* * *$ & & & & \\
\hline Frequency of prior interaction & $-.141(.135)$ & & & & & \\
\hline Importance of transaction & $.236(.169)$ & & & & & \\
\hline Dummy for second observation & $.859(.421)$ & $* *$ & $1.229(.137)$ & & $-.100(.049)$ & $* *$ \\
\hline$\sigma_{u}$ & 1.795 & & 2.463 & & .295 & \\
\hline$\sigma_{e}$ & 3.024 & & 7.850 & & .329 & \\
\hline$\rho^{b}$ & .260 & & .090 & & .446 & \\
\hline Model fit & \multicolumn{2}{|c|}{ Wald $\chi 2=36.47$} & \multicolumn{2}{|c|}{ Wald $\chi 2=13.67$} & \multicolumn{2}{|c|}{ Wald $\chi 2=82.48$} \\
\hline Estimation method & \multicolumn{2}{|c|}{$\begin{array}{l}\text { GLS, random effects } \\
(\mathrm{N}=210)\end{array}$} & \multicolumn{2}{|c|}{$\begin{array}{l}\text { GLS, random effects } \\
(\mathrm{N}=210)\end{array}$} & \multicolumn{2}{|c|}{$\begin{array}{l}\text { GLS, random effects } \\
\qquad(\mathrm{N}=210)\end{array}$} \\
\hline
\end{tabular}

$* \mathrm{p}<.10 ; * * \mathrm{p}<.05 ; * * * \mathrm{p}<.01$.

a: We use one-tailed tests for these posited directional hypotheses.

b: $\rho$ is the proportion of the total variance contributed by the panel-level variance component and calculated as $\rho$ $=\sigma_{\mathrm{u}}{ }^{2} /\left(\sigma_{\mathrm{u}}{ }^{2}+\sigma_{\mathrm{e}}{ }^{2}\right)$ 


\section{APPENDIX 1: MEASUREMENT SCALES AND ITEMS ${ }^{\mathrm{a}}$}

\begin{tabular}{|c|c|}
\hline Construct & Items \\
\hline $\begin{array}{l}\text { Contract Specificity } \\
\text { Cronbach's } \alpha=.67\end{array}$ & $\begin{array}{l}\text { 5-point scale }(1=\text { very little; } 5=\text { very much }) \\
\text { Terms in the formal agreements are sometimes very detailed and specific and at } \\
\text { other times left open. How specific were the contractual features with respect to } \\
\text { the following: } \\
\text { 1. Implementation procedures } \\
\text { 2. Financial and legal conditions } \\
\text { 3. Technical specifications } \\
\text { 4. Agreement as a whole }\end{array}$ \\
\hline $\begin{array}{c}\text { Buyer Lock-in } \\
\text { Cronbach's } \alpha=.76\end{array}$ & $\begin{array}{l}\text { 5-point scale }(1=\text { very small; } 5=\text { very large }) \\
\text { 1. If the product failed and had to be replaced, what would be the loss, in } \\
\text { terms of time and money, associated with purchasing a new product. } \\
\text { 2. If the product failed and had to be replaced, what would be the loss, in } \\
\text { terms of time and money, associated with training your personnel. } \\
\text { 3. If the product failed and had to be replaced, what would be the loss, in } \\
\text { terms of time and money, associated with data and information entry. } \\
\text { 4. If the product failed and had to be replaced, what would be the loss, in } \\
\text { terms of time and money, associated with stoppage at production } \\
\text { departments. }\end{array}$ \\
\hline
\end{tabular}

Binary Yes/No Response Format

Transaction Complexity What are the different kinds of products/services procured under this agreement?

(Multiple answers possible):

1. standard software $(1)^{\mathrm{b}}$

2. personal Computers (1)

3. work-stations (1)

4. peripherals (1)

5. cabling (1)

6. network configuration (2)

7. mini-computer (2)

8. mainframe (2)

9. computer driven machines (2)

10. industry specific software (3)

11. education (3)

12. instruction/training (3)

13. documentation (3)

14. support (4)

15. specialized software (4)

16. advice/consulting (4)

17. design (5)

18. customized software (5)

Measurement Ambiguity 5 -point scale $(1=$ very easy; $5=$ very difficult $)$

1. How difficult was it to judge the quality of the product/service at the time

Cronbach's $\alpha=.80$ of delivery?

2. How difficult was it to compare this product/service to similar products?

3. How difficult was it to compare the price/quality ratio of potential suppliers' products/services? 
Transaction Size What was the initial contract price (in Dutch Guilders)?

\begin{tabular}{|c|c|}
\hline $\begin{array}{l}\text { Frequency of Prior } \\
\text { Interaction }\end{array}$ & $\begin{array}{l}\text { 5-point scale }(1=\text { very infrequently; } 5=\text { very frequently }) \\
\text { How frequently did your organization do business with this supplier prior to this } \\
\text { focal transaction? }\end{array}$ \\
\hline $\begin{array}{l}\text { Importance of } \\
\text { Transaction }\end{array}$ & $\begin{array}{l}\text { 5-point scale }(1=\text { very little; } 5=\text { very much }) \\
\text { How important was this product for: } \\
\text { 1. The automation of your company. } \\
\text { 2. The profitability of your company. }\end{array}$ \\
\hline $\begin{array}{c}\text { Ex post Transaction } \\
\text { Problems }\end{array}$ & $\begin{array}{l}\text { 5-point scale }(1=\text { very little; } 5=\text { very much }) \\
\text { Listed below are some potential problems that could arise regarding the product, } \\
\text { its delivery, and its service. Please indicate how severe the problems were for each } \\
\text { of these items. } \\
\text { 1. Went over delivery schedule } \\
\text { 2. Went over price / budget } \\
\text { 3. Product incomplete } \\
\text { 4. Product to slow / limited } \\
\text { 5. Deviations from specifications made } \\
\text { 6. Incompatibility with other IT products } \\
\text { 7. Installation to hurried / sloppy } \\
\text { 8. Support to slow / too late } \\
\text { 9. Service too slow / late } \\
\text { 10.Necessary adjustments and customization too slow / late } \\
\text { 11.Incomplete / unclear documentation }\end{array}$ \\
\hline
\end{tabular}

Ex ante Contracting In number of working days, how much time did you and your colleagues spent on Costs negotiating and drafting the agreement with this supplier?

a: The original questionnaire was in Dutch. Items were translated into English by two individuals who were experts in English and Dutch.

b: Numbers in parentheses reflect the ratings on task complexity for each of the products/services and represent increasing demand for coordination between the buyer and seller .

c: Formative measure. 


\section{REFERENCES}

Anderson, Erin (1988). "Strategic Implications of Darwinian Economics for Selling Efficiency and Choice of Integrated of Independent Sales Forces" Management Science, 34 (5), 599-618.

Anderson, Eugene. W. and Mary W. Sullivan (1993), "The Antecedents and Consequences of Customer Satisfaction for Firms", Marketing Science, 12 (Spring), 125-43.

Anderson, Shannon W. and Henri C. Dekker (2005), "Management Control for Market Transactions: The Relationship Between Transaction Characteristics, Incomplete Contract Design and Subsequent Performance," Management Science, 51 (December), 1734-52.

Bajari, Patrick, Robert McMillan, and Steven Tadelis (2008), "Auctions versus Negotiations in Procurement: An Empirical Analysis," forthcoming Journal of Law, Economics, and Organization.

Barthelemy, Jerome (2008), "IT Outsourcing: The Goldilocks Strategy," The Wall Street Journal, December 15.

Batenburg, Ronald S., The External Management of Automation 1995. Codebook. ISCORE/ICS, Utrecht University, 1997: Chapter A

---- and Werner Raub (1995) "The External Management of Automation 1995". [data set] Utrecht University.

Beck, Nathaniel and Jonathan N. Katz (1995), "What to do (and what not to do) with Time-Series Cross Section Data," American Political Science Review, 89 (3), 634-47.

Bensaou, M. and Erin Anderson (1999), "Buyer-Supplier Relations in Industrial Markets: When Do Buyers Risk Making Idiosyncratic Investments?," Organization Science, 10 (July-August), 46081.

Bercovitz, Janet, Sandy D. Jap, and Jack A. Nickerson (2006), "The Antecedents and Performance Implications of Cooperative Exchange Norms," Organization Science, 17 (NovemberDecember), 724-40.

Buskens, Vincent, Werner Raub, and Jeroen Weesie (2000), "Networks and Contracting in Information Technology Transactions," in The Management of Durable Relationships:

Theoretical Models and Empirical Studies of Households and Organizations, Jeroen Weesie and Werner Raub (Eds.) Amsterdam: Thela Thesis.

Cannon, Joseph P. and Christian Homburg (2001), "Buyer-Supplier Relationships and Customer Firm Costs," Journal of Marketing, 65 (January), 29-43.

Cooil, Bruce, Russell S. Winer, and David L. Rados (1987), "Cross-Validation for Prediction," Journal of Marketing Research, 24 (3), 271-79.

Crocker, Keith J. and Scott E. Masten (1991), "Pretia Ex Machina? Prices and Process in Long-Term Contracts," Journal of Law and Economics, 34 (April), 69-99. 
Davidson, Russell. and MacKinnon, James. G. (1993), Estimation and Inference in Econometrics. New York, NY : Oxford University Press.

Dutta, Shantanu, Mark Bergen, Jan B. Heide, and George John (1995), "Understanding Dual Distribution: The Case of Reps and House Accounts," The Journal of Law, Economics \& Organization, 11 (1), 189-204.

Fornell, Claes and David F. Larcker (1981), "Structural Equation Models with Unobservable Variables and Measurement Error: Algebra and Statistics," Journal of Marketing Research, 18 (August), 382-88.

Garen, John (1984), "The Returns to Schooling: A Selectivity Bias Approach with a Continuous Choice Variable," Econometrica, 52 (5), 1199-1218.

---- (1988), "Compensating Wage Differentials and the Endogeneity of Job Riskiness," The Review of Economics and Statistics, 70 (February), 9-16.

Ghosh, Mrinal and George John (2005), "Strategic Fit in Industrial Alliances: An Empirical Test of Governance Value Analysis,” Journal of Marketing Research, 42 (3), 346-357.

---- and ---- (2009), "When Should Original Equipment Manufacturers use Branded Component Contracts with Suppliers?” Journal of Marketing Research, forthcoming (November).

Gilson, Ronald J. (1984), "Value Creation by Business Lawyers: Legal Skills and Asset Pricing," Yale Law Journal, 94 (2), 239-313.

Greene, William. H. (2003), Econometric Analysis, Upper Saddle River, NJ: Prentice Hall International.

Goldberg, Victor P. and John R. Erickson (1987), "Quantity and Price Adjustments in Long-term Contracts: A Case Study of Petroleum Coke," Journal of Law and Economics, 30 (2), 369-98.

Gulati, Ranjay and Jackson A. Nickerson (2008), "Interorganizational Trust, Governance Choice, and Exchange Performance," forthcoming Organization Science.

Hamilton, Barton H. and Jackson A. Nickerson (2003), "Correcting for Endogeneity in Strategic Management Research," Strategic Organization, 1 (1), 51-78.

Heckman, James J. (1979), "Sample Selection Bias as a Specification Error," Econometrica, 47 (1), 153-162.

Heide, Jan B. (1994), "Interorganizational Governance in Marketing Channels," Journal of Marketing, 58 (January), 71-85.

---- and George John (1990), "Alliances in Industrial Purchasing: The Determinants of Joint Action in Buyer-Supplier Relationships," Journal of Marketing Research, 27 (February), 24-36.

---- and Allen M. Weiss (1995), "Vendor Consideration and Switching Behavior in High-Technology Markets," Journal of Marketing, 59 (July), 30-43. 
Hill, Claire A. and Christopher King (2004), "How Do German Contracts Do As Much With Fewer Words?" Chicago-Kent Law Review, 79, 889-926.

Houston, Mark B. and Shane A. Johnson (2000), "Buyer-Supplier Contracts Versus Joint Ventures: Determinants and Consequences of Transaction Structure," Journal of Marketing Research, 37 (February), 1-15.

John, George, Allen M. Weiss, and Shantanu Dutta (1999), "Marketing in Technology-Intensive Markets: Toward a Conceptual Framework," Journal of Marketing, 63 (Special Issue), 78-91.

Kern, Thomas and Leslie P. Willcocks (2001), The Relationship Advantage: Information Technologies, Sourcing, and Management. Oxford: Oxford University Press.

Klein, Saul (1989), "A Transaction Cost Explanation of Vertical Control in International Markets," Journal of the Academy of Marketing Science, 17 (Summer), 253-260.

Leiblein, Michael J., Jeffrey J. Reuer, and Frederic Dalsace (2002), "Do Make or Buy Decisions Matter? The Influence of Organizational Governance on Technological Performance," Strategic Management Journal, 23, 817-833.

Lusch, Robert F. and James R. Brown (1996), "Interdependency, Contracting, and Relational Behavior in Marketing Channels," Journal of Marketing, 60 (October), 19-38.

Macneil, Ian R. (1980), The New Social Contract: An Inquiry into Modern Contractual Relations. New Haven: Yale University Press.

Masten, Scott E. and Edward A. Snyder (1993), "United States versus United Shoe Machinery Corporation: On the Merits," Journal of Law and Economics, 36 (1), 33-70.

Nordberg, Markus, Alexandra J. Campbell, and Alain Verbeke (1996), "Can Market-Based Contracts Substitute for Alliances in High Technology Markets?" Journal of International Business Studies, 27 (5), 963-979.

Pilling, Bruce K., Lawrence a. Crosby, and Donald W. Jackson Jr. (1994), "Relational Bonds in Industrial Exchange: An Experimental Test of the Transaction Cost Economics Framework," Journal of Business Research, 30 (July), 237-251.

Podsakoff, Philip M. and Dennis W. Organ (1986), "Self-Reports in Organizational Research: Problems and Prospects," Journal of Management, 12 (4), 531-44.

Rindfleisch, Aric and Jan B. Heide (1997), "Transaction Cost Analysis: Past, Present, and Future Applications," Journal of Marketing, 61 (October), 30-54.

Ramsey, James. B. (1969), "Test for Specification Errors in Classical Linear Least-Squares Regression Analysis", Journal of the Royal Statistical Society, Series B, 31 (2), 350-71.

Rosen, Susan R. (2004), Norms versus Behavior in OEM-Supplier Relationships: Antecedents and Outcomes in Intendedly Relational Exchanges. Unpublished dissertation, University of Minnesota. 
Sanchez, Ronald and Joseph T. Mahoney (1996), "Modularity, Flexibility, and Knowledge Management in Product and Organization Design," Strategic Management Journal, 17 (Winter Special Issue), 63-76.

Saussier, Stéphane (2000), "Transaction costs and contractual completeness: the case of Électricité de France " Journal of Economic Behavior \& Organization, 42, 189-206.

Shaver, J. Myles (1998), "Accounting for Endogeneity When Assessing Strategy Performance: Does Entry Mode Choice Affect FDI Survival?", Management Science, 44 (April) 571-85.

Stump Rodney L. and Jan B. Heide (1996), "Controlling Supplier Opportunism in Industrial Relationships," Journal of Marketing Research, 33 (November), 431-441.

Uzzi, Brian (1996), "The Sources and Consequences of Embeddedness for the Economic Performance of Organizations: The Network Effect," American Sociological Review, 61 (4), 67498.

Wathne, Kenneth H. and Jan B. Heide (2000), "Opportunism in Interfirm Relationships: Forms, Outcomes, and Solutions," Journal of Marketing, 64 (October), 36-51.

Weiss, Allen M. and Erin Anderson (1992), "Converting From Independent to Employee Salesforces: The Role of Perceived Switching Costs," Journal of Marketing Research, 29 (February), 101-15.

Weiss, Allen M. and Jan B. Heide (1993), "The Nature of Organizational Search in High Technology Markets," Journal of Marketing Research, 30 (May), 220-33.

Williamson, Oliver E. (1985), The Economic Institutions of Capitalism: Firms, Markets, Relational Contracting (2nd ed.). New York: The Free Press.

---- (1991), "Comparative Economic Organization: The Analysis of Discrete Structural Alternatives," Administrative Science Quarterly, 36, 269-296.

Wooldridge, Jeffrey M. (2001), Econometric Analysis of Cross Section and Panel Data (1st ed.). Cambridge, MA: the MIT press.

Wuyts, Stefan and Inge Geyskens (2005), "The Formation of Buyer-Seller Relationships: Detailed Contract Drafting and Close Partner Selection," Journal of Marketing, 69 (October), 102-17.

Zaheer, Akbar, Bill McEvily, and Vincenzo Perrone (1998), "Does Trust Matter? Exploring the Effects of Interorganizational and Interpersonal Trust on Performance " Organization Science, 9 (2), 141-59.

Zeithaml, Valarie. A., Leonard. L. Berry and A. Parasuraman (1996), "The Behavioral Consequences of Service Quality", Journal of Marketing, 60 (April) 31-46. 


\section{FOOTNOTES}

$1 \quad$ The observed level might not mirror the expected level for a variety of reasons, including randomness, reputation and corporate culture (Kreps 1990), agency problems between different levels of managers, inertia, or even corporate policy. For instance, many institutions (e.g., the US Department of Defense, General Motors Corporation, and the European Organization for Nuclear Research - CERN) have strict guidelines and policies on what is (or is not) permissible in written contracts.

2 Our context of "capital" IT equipment and software purchases should be distinguished from the "service-oriented" IT outsourcing sector where customer firms outsource the management, either partially or wholly, of their IT infrastructure administration, management, and maintenance.

3 For instance, in their analysis of the seminal United Shoe Machinery Corporation anti-trust case, Masten and Snyder (1993) document that the quality of these machines and associated after-sales service was critical to keep the shoe manufacturing operation functioning smoothly; yet the accounting cost of all these machines in a manufacturing operation/plant was barely $2 \%$ of the yearly revenue of the shoe manufacturers. The shoe manufacturer's contracting hazards are hence far greater than just the loss of the capitalized value of a non-performing equipment.

4 It is also important to note that it is precisely these deviations (or mistakes) that enable us to address the econometric identification considerations that are essential for the performance analysis.

5 See Batenburg, Ronald S., The External Management of Automation 1995. Codebook. ISCORE/ICS, Utrecht University, 1997: Chapter A.

6 We have verified whether using either the first or the second indicator alone in our first stage equations resulted in significantly different findings. All findings remained essentially the same.

7 We used the bootstrapping technique to assess robustness and cross validate our results (Cooil, Winer, and Rados 1987). The differences in standard errors between our FGLS and bootstrapping did not result in any significant changes in the reported values, thereby suggesting that the results were robust to distributional assumptions.

8 In our case, this endogeneity arises out of selectivity bias (Heckman 1979). However, endogeneity can also arise from other sources including omitted variables, unobserved measurement errors, and bi-directional causality (e.g., as seen in panel data when firms set advertising budgets based on past sales and current sales are impacted by current level of advertising expenditure).

9 We conducted a Hausman test to assess whether the difference in coefficients between our random effects model and an alternative fixed effects model were significant. Our results $(p>0.10)$ indicate this was not the case. Hence, consistent with common practice, we prefer and report the random effects models (Greene 2003). 